\title{
Взаимосвязь между размерами корневой системы и генетическим статусом локуса Vrn-1 у мягкой пшеницы (Triticum aestivum L.)
}

Пшеничникова Т.А. ${ }^{*}$, к.б.н., зав. сектором генетики качества зерна, Симонов А.В., к.б.н., н.с., Морозова Е.В., м.н.с., Смирнова О.Г., к.б.н., с.н.с. ФГБНУ «Федеральный исследовательский центр Институт цитологии и генетики Сибирского отделения Российской академии наук».

*e-mail:wheatpsh@bionet.nsc.ru

Архитектура корневой системы определяет укоренение растения, эффективное поглощение питательных веществ и воды из почвы и взаимодействие с биомом почвы. В данной работе у пшеницы (Triticum aеstivum L.) была изучена взаимосвязь между аллельным состоянием локуса Vrn-1 и длиной и весом корней. Было обнаружено, что присутствие доминантных аллелей генов Vrn-A1 и Vrn-B1 аналогично действию длительной яровизации. При этом происходит уменьшение размеров корневой системы одновременно с сокращением периода до иветения. Наибольший эффект оказывает ген Vrn-A1.

Ключевые слова: Triticum aеstivum, интрогрессия, длина и вес корней, моносомный анализ; локус Vrn-1.

\section{Relationship between the size of the root system and the genetic status of lo- cus Vrn-1 in bread wheat (Triticum aestivum L.)}

Pshenichnikova T.A., Simonov A.V., Morozova E.V., Smirnova O.G. Institute of Cytology and Genetics, Siberian Branch of Russian Academy of Sciences, Novosibirsk, Russia

E-mail:wheatpsh@bionet.nsc.ru

Root architecture determines the rooting of the plant, the effective absorption of nutrients and water from the soil and the interaction with the soil biome. In this work, the relationship between the allelic state of the Vrn-1 locus and the length and weight of the roots was studied in wheat (Triticum aestivum L.). It was found that the presence of dominant alleles of the Vrn-Al and Vrn-BI genes is similar to the effect of prolonged vernalization. In this case, a reduction in the size of the root system occurs simultaneously with a reduction in the period before flowering. The Vrn-Al gene has the greatest effect.

Key words: Triticum aestivum, introgression, root weight and length, monosomic analysis; Vrn-1 locus.

Корни - это основной орган растительного организма, формирующийся на первых этапах его развития. Архитектура корневой системы опре- 
деляет укоренение растения, эффективное поглощение питательных веществ и воды из почвы и взаимодействие с биомом почвы. Хорошо развитая мелкая корневая система способна улавливать влагу даже при небольших дождях, а длинные корни способны достигать нижних, более увлажненных горизонтов почвы. Эти свойства особенно важны в условиях засухи, которые в настоящее время представляют наиболее серьезную угрозу климату во всем мире.

Исследования по генетическому контролю корневой системы у хлебной пшеницы (Triticum aestivum L.) значительно отстают от аналогичных исследований по рису и кукурузе и ограничены поиском QTL в различных популяциях [1-3]. Локусы, идентифицированные в этих исследованиях, были локализованы на хромосомах практически всех гомеологических групп, что говорит о сложном генетическом контроле данного признака. В недавнем исследовании было обнаружено, что локус $V r n-1$ участвует в генетическом контроле роста корня и определяет такие фенотипические особенности, как угол и длина корня [4]. В данной работе с помощью моносомного анализа у пшеницы была изучена взаимосвязь между аллельным состоянием локуса $V r n-1$ и длиной и весом корней. В качестве генетического материала послужила озимая интрогрессированная линия (IL) 5D-5, полученная ранее на основе замещенной линии Чайниз Спринг (Синтетик 6x 5D). Донором хромосомы является озимый синтетик гибридного происхождения (T. dicoccoides $\times$ Ae. tauschii, AABBDD). Также был изучен набор из 8 сортов и линий различного состава по генам локуса Vrn-1. Растения изучались в условиях теплицы, в условиях гидропонного выращивания. Моносомные популяции $\mathrm{F}_{2}$ по хромосомам 5A, 5B и 5D были получены на основе соответствующих моносомных линий ярового сорта Саратовская 29 (С29). По 130 растений было изучено в каждой популяции по длине и весу корней. Во втором эксперименте у каждого из сортов и линий было изучено по 12 растений. Длину корней (см) измеряли после извлечения из искусственного грунта, вес корней (г) - после полного высушивания на воздухе.

Таблица 1 - Среднее число дней до цветения, длина корня и его вес у гибридов $\mathrm{F}_{2}$ между моносомными линиями по хромосомам 5A, 5B и 5D ярового сорта С29 и интрогрессированной линией (IL) 5D-5

\begin{tabular}{|c|c|c|c|}
\hline Генотипы & $\begin{array}{c}\text { Дни } \\
\text { до цветения }\end{array}$ & $\begin{array}{c}\text { Длина } \\
\text { корней, см }\end{array}$ & $\begin{array}{c}\text { Вес } \\
\text { корней, г }\end{array}$ \\
\hline 1 & 2 & 3 & 4 \\
\hline $\mathrm{C} 29(V r n-A 1 ; V r n-B 1 ; v r n-D 1)$ & 36,1 & 22,1 & 0,103 \\
\hline $\begin{array}{l}\text { IL 5D-5 (vrn-A1; vrn-B1; vrn-Dl) } \\
\text { яровизация } 30 \text { дней }\end{array}$ & 49,3 & 30,2 & 1,04 \\
\hline $\begin{array}{l}\text { IL 5D-5 (vrn- } A 1 \text {; vrn-B1; vrn-Dl) } \\
\text { яровизация } 60 \text { дней }\end{array}$ & 37,0 & 22,8 & 0,090 \\
\hline $\begin{array}{l}\mathrm{F}_{2} \text { моно 5A C29 х IL 5D-5 } \\
(v r n-A 1 ; V r n-B 1 ; v r n-D 1)\end{array}$ & $47,4 * * *$ & $28,4 * * *$ & $0,437 * * *$ \\
\hline
\end{tabular}




\begin{tabular}{|l|c|c|c|}
\hline \multicolumn{1}{|c|}{$\mathbf{1}$} & $\mathbf{2}$ & $\mathbf{3}$ & $\mathbf{4}$ \\
\hline $\begin{array}{l}\text { F2 моно 5B C29 x IL 5D-5 } \\
(\text { Vrn-A1; vrn-B1; vrn-D1) }\end{array}$ & 37,3 & $24,9^{*}$ & $0,278^{* * *}$ \\
\hline $\begin{array}{l}\text { F } 2 \text { моно 5D C29 x IL 5D-5 } \\
(\text { Vrn-A1; Vrn-B1; vrn-D } 1)\end{array}$ & 36,2 & 23,4 & $0,138^{* *}$ \\
\hline
\end{tabular}

$\mathrm{P}<0,05 ; * * \mathrm{P}<0,01 ; * * * \mathrm{P}<0,001$ по сравнению с С29 (критерий Стьюдента)

В таблице 1 представлены средние данные о размере корневой системы в моносомных популяциях сорта С29. При 60-дневной яровизации было обнаружено примерно равное значение трех признаков между озимой линией 5D-5 и яровым сортом S29. В моносомной популяции по хромосоме 5 А большинство растений лишены наиболее эффективного доминантного аллеля гена Vrn-Al сорта С29. Вариабельность по дате цветения определяют аллели генов $V r n-B 1$ и $V r n-D 1$. В этом случае цветение в популяции происходило на 10 дней позже по сравнению с C29, а длина и вес корней были самыми большими. В моносомных популяциях по хромосомам 5B и 5D, где присутствует ген $V r n-A 1$, среднее число дней до цветения было приблизительно равно С29. В моносомной популяции по хромосоме 5В длина и вес корней были значительно выше, чем у реципиентного сорта. Корни были на 2,8 см длиннее и весили в 2,7 раза больше. В моносомной популяции по хромосоме 5D длина корней была такой же, как и у C29, тогда вес был в 1,3 раза выше. Таким образом, присутствие доминантных аллелей генов Vrn-Al и Vrn$B 1$ аналогично действию длительной яровизации на линию 5D-5: происходит уменьшение размеров корневой системы одновременно с сокращением периода до цветения. При этом наибольший эффект оказывает ген Vrn-A1. Сходный эффект мы наблюдали среди 8 сортов и линий пшеницы - носителей различных комбинаций аллелей локуса $\operatorname{Vrn}-1$ (табл. 2).

Таблица 2 - Среднее значение числа дней до цветения, длины и веса корней у генотипов с различной комбинацией генов локуса $V r n-1$

\begin{tabular}{|c|c|c|c|}
\hline Генотипы & $\begin{array}{c}\text { Дни до } \\
\text { цветения }\end{array}$ & $\begin{array}{l}\text { Длина кор- } \\
\text { ней, см }\end{array}$ & $\begin{array}{l}\text { Вес кор- } \\
\text { ней, Г }\end{array}$ \\
\hline $\mathrm{C} 29(V r n-A 1 ; V r n-B 1 ; v r n-D 1)$ & 40,2 & 22,1 & 0,32 \\
\hline Янецкис Пробат (Vrn-A1; Vrn-B1; vrn-D1) & 43,7 & 25,8 & 0,40 \\
\hline Новосибирская 67 (Vrn-A1; Vrn-B1; vrn-D1) & 41,3 & 25,8 & 0,30 \\
\hline Диамант $2(V r n-A 1 ; V r n-B 1 ; v r n-D 1)$ & 42,6 & 21,8 & 0,23 \\
\hline $\begin{array}{l}\text { Линия } 821 \text { (с интрогрессиями от } \\
\text { T. timopheevii, на основе C29) }\end{array}$ & 42,5 & 32,0 & 0,76 \\
\hline Мильтурум 553 (vrn-A1; Vrn-B1; vrn-D1) & 46,9 & 28,6 & 1,18 \\
\hline Дуванка $501(\mathrm{v} r n-A 1 ; V r n-B 1 ; v r n-D 1)$ & 50,8 & 29,7 & 0,80 \\
\hline Синтетик 6x (vrn-A1; vrn-B1; vrn-D1)* & $45,5^{*}$ & 30,2 & 1,22 \\
\hline Чайниз Спринг (vrn-A1; vrn-B1; Vrn-Dl) & 47,4 & 26,9 & 1,1 \\
\hline
\end{tabular}

* - при яровизации 30 дней 
Среди 8 генотипов только один - озимый. Даже после 30-дневной яровизации он имел наибольшую длину и вес корней. Средняя продолжительность периода «посев-цветение» четырех яровых генотипов - носителей гена $V r n-A 1$ была достоверно ниже, чем у четырех последних $(\mathrm{t}=3.50 ; \mathrm{P}<0,01)$. Генотипы, у которых этот ген отсутствовал, но присутствовал ген Vrn-B1, имели достоверно более длинные корни $(\mathrm{t}=3.50 ; \mathrm{P}<0,01)$ и имели более высокий вес корней $(\mathrm{t}=3.50 ; \mathrm{P}<0,01)$. Линия 821 с интрогрессиями от тетраплоидного вида T. timopheevii, достоверно не отличалась по дате цветения от родительского сорта С29. Однако она, также, как и генотипы - носители гена $V r n-B 1$, имела достоверно более длинные корни и более высокий вес корней. По ранее полученным данным, линия несет интрогрессию в хромосоме $5 \mathrm{~A}$ [5]. Возможно, линия 821 унаследовала новый аллель гена $V r n-1$, который не столь значительно уменьшает размеры корней. Наши данные совпадают с данными австралийских ученых, которые считают, что именно этот ген мягкой пшеницы среди трех генов локуса $V r n-1$ оказывает наибольшее влияние на развитие корневой системы корня [4].

Благодарности: Работа поддержана грантом РФФИ № 19-416-540001 и соглашением р-94 (от 21.06.2019) с Новосибирской областью. Растения выращивались в ЦКП ЛИВР ИЦиГ СО РАН, бюджетный проект №0324-20190039-С-001. Выражаем благодарность Н.М. Ковалевой за техническое сопровождение эксперимента.

\section{Список литературы}

1. Kabir M.R., Liu G., Guan P., Wang F., Khan A.A., Ni Zh., Yao Y., Hu Z.H., Xin V., Peng H., Sun Q. Mapping QTLs associated with root traits using two different populations in wheat (Triticum aestivum L. // Euphytica. 2015. V.206. P.175-190.

2. Ehdaie B., Mohammadi S.A., Nouraein M. QTLs for root traits at mid-tillering and for root and shoot traits at maturity in a RIL population of spring bread wheat grown under well-watered conditions // Euphytica, 2016. V.211. P.17-38.

3. Liu P., Jin Y., Liu J., Liu C., Yao H., Luo F., Guo Z., Xia X., He Z. Genome-wide association mapping of root system architecture traits in common wheat (Triticum aestivum L.) // Euphytica. 2019. V.215. P.121.

4. Voss-Fels K.P., Hannah Robinson H., Mudge S.R., Richard C., Newman S., Wittkop B. et al. VERNALIZATION1 modulates root system architecture in wheat and barley // Molecular Plant. 2018. V.11. P.226-229.

5. Leonova I.N., Kalinina N.P., Budashkina E.B., Röder M.S., Salina E.A. Comparative molecular and genetic analysis of Triticum aestivum $\times$ Triticum timopheevii hybrid lines resistant to leaf rust // Proc. 11th EWAC Conf., Novosibirsk, 2001. 